\title{
Ankara Keçisinde (Capra hircus) dil papillalarının ışık ve taramalı elektron mikroskobik yapısı üzerine incelemeler: I. Tat papillaları*
}

\author{
Burhan Toprak $^{1 *}$ (), Selami Candan² (), Nurcan Özyurt Koçakoğlu3 ${ }^{(0)}$ \\ ${ }^{7}$ Veteriner Kontrol Merkez Araştırma Enstitüsü, Genetik Laboratuvarı, Ankara, Türkiye \\ 2,3 Gazi Üniversitesi, Fen Fakültesi, Biyoloji Bölümü, Ankara, Türkiye
}

Geliş Tarihi / Received: 05.10.2020, Kabul tarihi / Accepted: 05.11.2020

\begin{abstract}
Özet: Bu çalışmada Ankara keçisi dilindeki tat papillalarının yapısı ışık (IM) ve taramalı elektron mikroskobuyla (SEM) incelendi. Çalışmada dört adet erişkin dişi Ankara keçisi dilleri kullanıldı. Işık ve taramalı elektron mikroskobu için dil örnekleri, dilin üst yüzünün apex, corpus, radix ve torus lingua bölgeleri ile dil ucunun alt yüzünden alındı. Ankara keçisi dilinde papilla fungiformis ve papilla vallata olmak üzere iki tip tat papillası gözlendi. Papilla fungiformis'ler, dil ucunun altı, dilin uç ve gövde kısmının üst yüzü ile yanlarında ve torus lingua'nın her iki yan tarafında tespit edildi. Bu papillalar, yuvarlak ve mantar şeklinde olup morfolojileri bulundukları yerlere göre farklılık göstermekteydi. SEM incelemelerinde, papilla fungiformis'lerin üst yüzeyinde tat porusları görüldü. Işık mikroskobu kesitlerinde bu papillaların tepesindeki epitel tabakada tat tomurcukları mevcuttu. Papilla vallatalar, dilin torus lingua bölgesinin her iki arka yan kısmında gözlendi. Bu papillaların etrafı belirgin bir hendekle çevriliydi ve annülar pedler mevcuttu. SEM incelemelerinde, papillaların yüzeyi düzdü ve yüzeye açılan tat porusları mevcut değildi. IM incelemesinde, papilla vallata tat tomurcuklarının papillanın hendeğe bakan duvarında intraepiteliyal olarak bulundukları gözlendi. Ankara keçisi dilindeki tat papillalarının ışık ve taramalı elektron mikroskobik yapısı incelenerek diğer ruminant türleriyle olan benzerlikleri ve farklılıkları belirlendi.
\end{abstract}

Anahtar kelimeler: Ankara keçisi, ışık mikroskop, taramalı elektron mikroskop, tat papillaları, tat tomurcuğu

\section{Investigations on the light and scanning electron microscopic structure of the lingual papillae in the Angora Goat (Capra hircus): I. Gustatory papillae}

\begin{abstract}
In this study, the structure of the gustatory papillae on tongue in the Ankara goat was examined by light (LM) and scanning electron microscope (SEM). In the study, tongues of four adult female Angora goats were used. For Light and Scanning Electron Microscope, lingual samples were taken from the apex, corpus, radix and torus regions of the dorsal lingual surfaces with ventral surface of tongue tip. Two types of gustatory papillae as fungiform and vallate papillae were observed on the tongue of the Angora goat. The fungiform papillae were detected on the ventral surface of tongue tip, dorsal and lateral parts of the lingual apex and body with both sides of the torus lingua. These papillae were round and mushroom like shape and their morphology displayed variety according to their location. In the SEM investigations, on the dorsal surface of fungiform papillae were observed taste pores. In LM examinations, taste buds were found in the epithelium of the dorsal parts of these papillae. The vallate papillae were observed on both caudo-lateral sides of the torus lingua. These papillae were encircled with a prominent papillary groove and there were annular pads. In SEM examinations, the surfaces of these papillae were flat and the taste pores opened to the surface were absent. In LM examinations, taste buds of vallate papillae were observed in the epithelium of the inner trench walls of the papillae. As a result, the light and scanning electron microscopic structure of the gustatory papillae on the tongue of Angora goat were examined and their similarities and differences with other ruminant species were determined.
\end{abstract}

Keywords: Angora goat, gustatory papillae, light microscopy, scanning electron microscopy, taste bud

\section{Giriş}

Dil, beslenmede ağız boşluğundaki diğer organlarla birlikte önemli bir rol oynar. Dilin memelilerdeki morfolojik ve histolojik özellikleri, canlılardaki beslenme tarzları arasındaki farklılıkların bir yansımasıdır (Iwasaki 2002). Memeli hayvanlarda dil üzerinde mekanik etkili ve tat duyusunu alan dil papillaları vardır. Mekanik etkili papillalar yiyeceklerin alınmaSı, parçalanması ve yutulmasında görev alırlar. Tat duyusunu alan papillalar ise tatlı, acı, ekşi, tuzlu v.b. tatların alınmasını sağlayarak besin seçiminde rol oynamaktadırlar.

\footnotetext{
* Bu çalışma "Light and Scanning Electron Microscopic Structure of Gustatory Papillae on Tongue in the Angora Goat (Capra hircus)" başlıkla I. Uluslararası Türkiye Veteriner Anatomi Kongresi. X. Ulusal Veteriner Anatomi Kongresi. 13-16 Eylül 2017, Sandıkl/Afyonkarahisar kongresinde bildiri olarak sunulmuştur.
}

Yazışma adresi / Correspondence: Burhan Toprak, Veteriner Kontrol Merkez Araştırma Enstitüsü, Genetik Laboratuvarı, Keçiören-Ankara E-Posta: burhan.toprak@tarimorman.gov.tr

ORCID IDs of the authors: ${ }^{10000-0003-1082-4559 \cdot 20000-0002-7402-1360 ~ • ~ 30000-0001-7137-8631 ~}$ 
Şimdiye kadar birçok hayvan türünde dildeki papillaların tipleri, dağılımları, ışık mikroskobik yapISI, SEM ve TEM özelliklerini gösteren çalışmalar yapılmıştır. Çift tırnaklı hayvanların değişik tür ve ırklarında dildeki hem tat hem de mekanik etkili papillaların ışık ve taramalı elektron mikroskobik yapıları incelenmiştir. Buna göre Jamunapari keçisi (Kumar ve ark. 1998), formason keçi antilobu (Atoji ve ark. 1998; Takayuki ve ark. 2002), kara antilobu (Emura ve ark. 1999), berberi koyunu (Emura ve ark. 2000), bighorn koyunu (Takayuki ve ark. 2002), mehraban kuzusu (Tadjalli ve Pazhoomand 2004), Saanen keçisi (Kurtul ve Atalgın 2008) ve Markhoz keçisi (Goodarzi ve Hoseini 2015) gibi evcil ve yabani çift tırnaklı hayvanlarda dil papillalarının taramalı elektron mikroskobik yapıları incelenmiştir.

Cüce geyik (Agungpriyono ve ark. 1995), Akkaraman koyunu (Harem ve ark. 2009), Zavot ineği (Karadag Sarı ve ark. 2010), keçi (Fonseca ve ark. 2011), gazel (Kocak Harem ve ark. 2011), alpaka (Gozdziewska-Harłajczuk ve ark. 2015) ve sığır-yakda (Yanping ve ark. 2016) dil papillalarının hem ışık hem de taramalı elektron mikroskobik yapıları ortaya konulmuştur.

Bir step hayvanı olan Ankara keçisi (Capra hircus), 800 metreden daha yukarı rakımlarda, kuru ve az yağışlı iklim tipine sahip Orta Anadolu'da yetişir. Bu hayvanlar, alçak arazide ve rutubetli ortamlarda yaşayamazlar. Ankara ilinin Ayaş, Beypazarı ve Güdül ilçeleri başta olmak üzere, İç Anadolu bölgesi ile Güneydoğu ve Doğu Anadolu bölgesinin bazı illerinde yetiştirilmektedirler. Başta tiftik olmak üzere et ve deri ticareti için yetiştirilir. Dünyanın en kaliteli tiftikleri, Ankara'da yetiştirilen keçilerden elde edilmektedir. Bölgenin iklim şartları, bitki örtüsü ve keçinin beslenme şekli tiftiğin kalitesinde etkili olmaktadır.

Ankara keçisi, bozkır ortamına mükemmel bir şekilde uyum sağlamıştır. Kapalı ve ağıl ortamında uzun süre kalamazlar. En ağır kış şartlarında bile meradan azami oranda yararlanırlar. Oldukça hareketli olan Ankara keçileri, uçtan ve taze otlarla beslenirler. Bunların yanı sıra çalı, diken ve ağaç yapraklarını da severek tüketirler.

Sunulan bu çalışma, Ankara keçisinin dilinde bulunan tat papillalarının ışık ve taramalı elektron mikroskobik yapılarının incelenmesi amacıyla yapılmıştır.

\section{Gereç ve Yöntem}

Çalışmada Ankara'nın Güdül ilçesinden sağlanan kasaplık dört adet erişkin dişi Ankara keçisi materyal olarak kullanıldı. Yerel bir mezbahada kesim yapıldıktan hemen sonra taze olarak alınan diller, serum fizyolojik ile yıkandı. ışık ve taramalı elektron mikroskobu için dil örnekleri, dilin üst yüzünün apex, corpus, radix ve torus lingua bölgeleri ile dil ucunun alt yüzünden alındı.

Taramalı elektron mikroskobik incelemeler için dil örnekleri, \%10'luk formaldehit'te tespit edildi. Daha sonra FAA'de (\%10 Formaldehit-\%5 Asetik Asit-\%85 Alkol) ikinci tespit yapıldı. Bu tespit sonrası çok kısa bir sürede normal hava şartlarında kurutma gerçekleştirildi. Kurutulan dil örnekleri SEM incelemesi için stublara yerleştirildi. Bu örneklerin altınla kaplanması sonrası 5-10 kV aralığında JEOL JSM 6060 LV taramalı elektron mikroskobunda inceleme yapılarak fotoğraflandı.

Işık mikroskobik incelemeler için dil örnekleri, \%10'luk formaldehitte tespit edildi. Daha sonra dokulardan yıkama, dehidrasyon, parafine doyurma ve gömme işlemleri yapıldı. Elde edilen parafin bloklardan $6 \mu \mathrm{m}$ kalınlığında kesitler alındı. Alınan bu kesitler, Mallory'nin üçlü boyası ve H\&E boyası ile boyandı. Bu kesitler, Olympus CX21 ışık mikroskobunda incelendi ve fotoğraflandı.

\section{Bulgular}

Ankara keçisi dili ortalama olarak $12 \mathrm{~cm}$ uzunluğundaydı. Dil üzerinde apex, corpus ve radix lingua olmak üzere üç kısım ayırt edildi. Dilin apex lingua'sı üzerinde düzensiz bir sulcus medianus gözlendi. Dildeki corpus lingua üzerinde oldukça iyi gelişmiş bir torus lingua ve bunun ön kısmında belirgin bir fossa lingua tespit edildi (Şekil 1a). Dil üzerinde papilla filiformis, papilla conica ve papilla lentiformis olmak üzere 3 tip mekanik papilla ile papilla fungiformis ve papilla vallata olmak üzere iki tip tat papillası görüldü (Şekil 1b, 1c, 1d, 1e, 1f, 1g).

Papilla fungiformis'lerin, papilla filiformis'ler arasında dağılmış halde dilin üst yüzünde, dil ucunun altında, dil gövdesi boyunca yanlarda ve torus lingua'nın yanlarında yer aldıkları görüldü. Bunlar dil ucunun üstünde (Şekil 2a) ve altında (Şekil 3a) yoğun olarak bulunmaktaydılar. Dil gövdesinin yanlarında ve torus lingua bölgesinde yer alanların sayısı daha azdı (Şekil 4a). Dilin üst kısmında sulcus medianus'un sonlandığı yerden fossa lingua'ya kadar olan median hatta papilla fungiformis'ler görülmedi (Şekil 2a, Şekil 4a). Dil ucunun üst ve altındaki papilla fungiformis'lerin dil gövdesinin yanları ve torus lingua'da yer alanlardan daha küçük oldukları tespit edildi. 


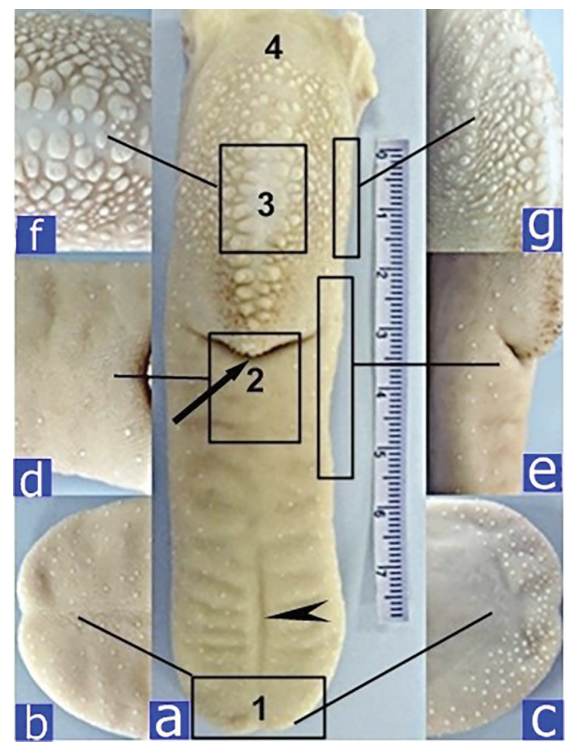

Şekil 1-a) Dilin üst yüzeyinin makroskobik genel görünümü. 1: Apex lingua, 2: Corpus lingua, 3: Torus lingua, 4: Radix lingua, Ok başı: Sulcus medianus, ok: Fossa lingua. b) Dil ucunun üst yüzeyindeki papilla fungiformis'ler, c) dil ucunun alt yüzündeki papilla fungiformis'ler, d) dil gövdesindeki papilla fungiformis'ler, e) torus lingua'nın yanındaki papilla fungiformis'ler, f) torus lingua'daki papilla lentiformis ve papilla conica'lar, g) Papilla vallata'ların görünümü.

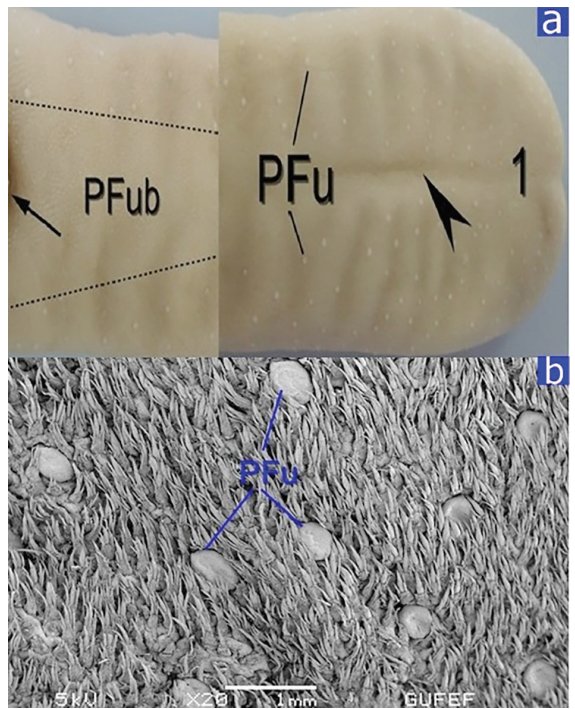

Şekil 2-a) Dil ucunun üst yüzeyindeki ve dil gövdesinin yanlarındaki papilla fungiformis'ler. 1: Dil üst ucu, Ok başı: Sulcus medianus, PFu: Papilla fungiformis'ler, PFub: Papilla fungiformis'lerin olmadığı bölge, Ok: fossa lingua. b) Dil ucunun üst yüzündeki papilla fungiformis'lerin taramalı elektron mikroskopta düşük büyültmede görünümü. $\mathbf{P F u}$ : Papilla fungiformis'ler.

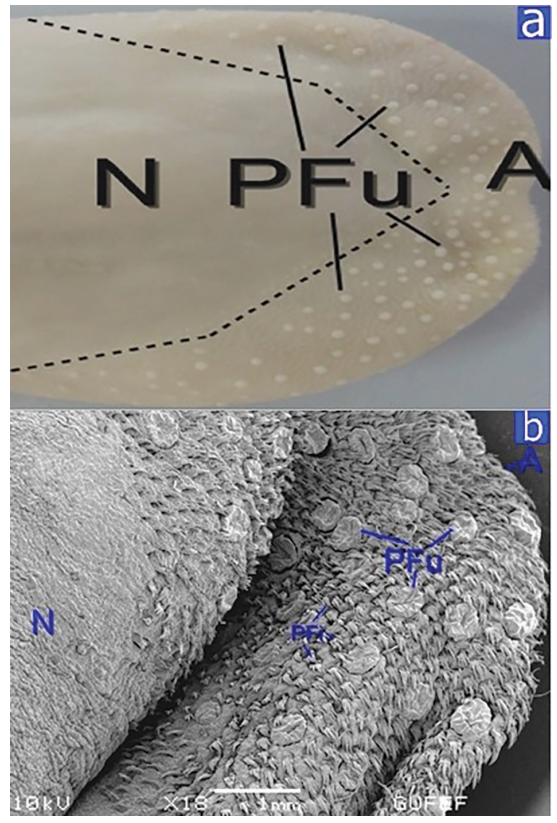

Şekil 3-a) Dil ucunun alt yüzündeki papilla fungiformis'ler A: Dil alt ucu, PFu: Papilla fungiformis'ler, N: Dil ucu altında herhangi bir papillanın bulunmadığı bölge. b) Dil ucunun altındaki papilla fungiformis'lerin taramalı elektron mikroskopta düşük büyültmede görünümü. $\mathrm{A}: \mathrm{Di}$ ucu, N: Dil ucunun altında herhangi bir papillanın bulunmadığı bölge, PFu: Papilla fungiformis'ler, PFi: Papilla filiformis'ler.

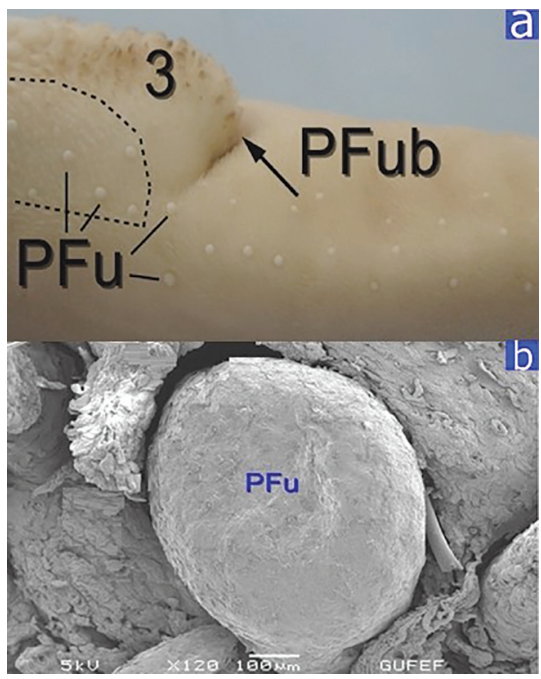

Şekil 4-a) Torus lingua'nın yanındaki papilla fungiformis'ler. PFu: Papilla fungiformis'ler, PFub: Papilla fungiformis'lerin bulunmadığı bölge. 3: Torus lingua, ok: Fossa lingua. b) Dilin torus lingua bölgesinde yer alan bir papilla fungiformis'in taramalı elektron mikroskobik görünümü. PFu: Papilla fungiformis. 
Taramalı elektron mikroskobik incelemede, papilla fungiformis'lerde dilde bulundukları yerlere göre morfolojik olarak farklılıklar görüldü. Eliptik veya yuvarlak şekilli mantara benzeyen bu papillalar, belirgin bir sulcus ile papilla filiformisler'den ayrılmaktaydı. Dil ucunun üstünde yer alan papilla fungiformis'ler, daha düzgün bir yüzeye sahip olmasına rağmen, bazılarında çukurluklar görüldü (Şekil $2 \mathrm{~b}$ ve Şekil $5 \mathrm{a}$ ). Bu bölgedeki papillaların ortalama çapları 360-484 $\mu \mathrm{m}$ arasında değişmekteydi. Dil ucunun altındaki papilla fungiformis'lerin yüzeyleri dalgalı ve buruşuk bir bezelye görünümündeydi (Şekil 3b ve Şekil 6a). Burada yer alan papilla fungiformis'lerin çapları 352-489 $\mu \mathrm{m}$ arasında değişmekteydi. Dil gövdesinin yanlarında ve torus lingua'nın yan kısımlarında daha seyrek olarak bulunan papilla fungiformis'ler, daha büyük ve düzgün bir yüzeye sahiptiler (Şekil 4b). Buradaki papillaların çapı 642$653 \mu \mathrm{m}$ arasında değişmekteydi. Her üç bölgede de papillaların yüzeyinde ağız boşluğuna açılan tat porusları gözlendi. Papilla fungiformis'ler yüzeyinden yapılan yüksek büyültmelerde yüzey epitel hücrelerinin sınırları belirgindi. Epitel hücreler yüzeyinde micropit'ler ve microridge'ler tespit edildi. (Şekil 5b ve şekil $6 b$ ).

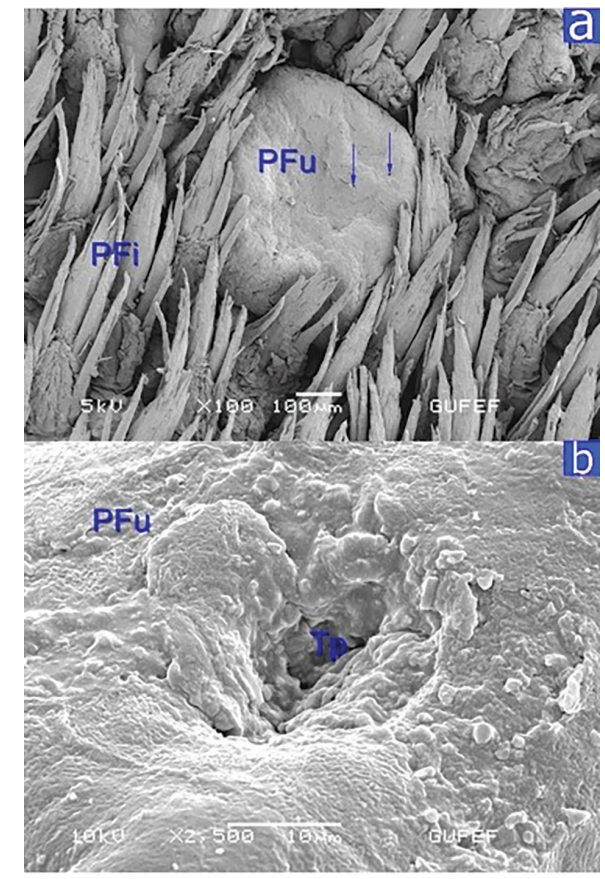

Şekil 5-a) Dil ucunun üst yüzünde yer alan bir papilla fungiformis'in taramalı elektron mikroskopta görünümü. PFu: Papilla fungiformis, PFi: Papilla filiformis'ler, Oklar: Tat porusları b) Bir papilla fumgiformis tat porusunun taramalı elektron mikroskopta yüksek büyültmede görünümü. PFu: Papilla fungiformis, Tp: Tat porusu.

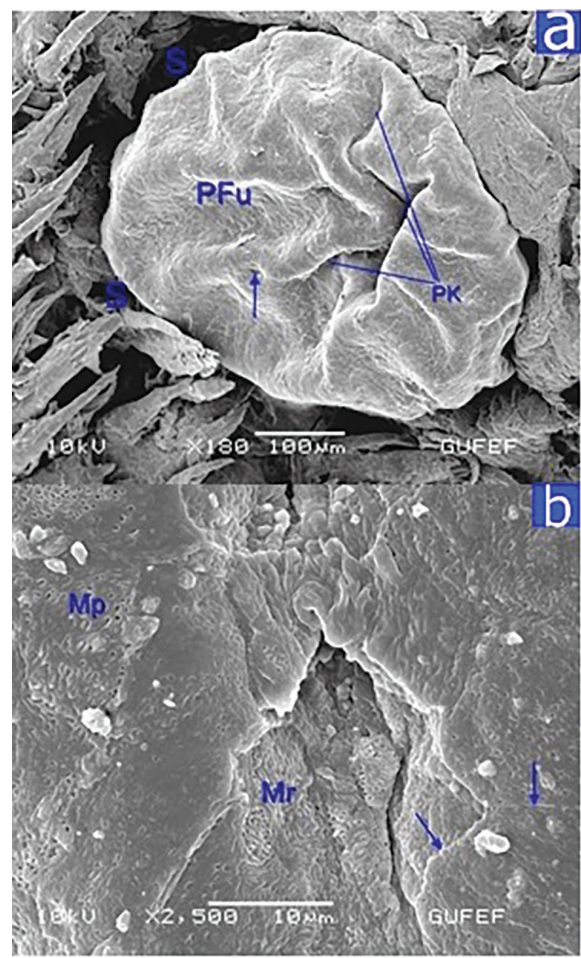

Şekil 6-a) Dil ucunun altındaki bir papilla fungiformis'in taramalı elektron mikroskobik görünümü. PFu: Papilla fungiformis'ler, S: Papilla fungiformis'leri etrafındaki papilla filiformis'lerden ayıran papilla yarığı, PK: Papilla yüzeyindeki yüzey kıvrımları, Ok: Tat porusu. b) Dil ucunun altındaki bir papilla fungiformis ve papillaya ait bir tat porusunun taramalı elektron mikroskopta yüksek büyültmede görünümü. Mp: Papilla yüzey epitelindeki çukurlar, Mr: Papilla yüzey epitelindeki çıkıntlar, Oklar: Yüzey epiteli hücre sınırları.

Işık mikroskopik incelemede, papilla fungiformis'ler çok katlı yassı bir epitel ile örtülüydü ve epitel yüzeyinde zayıf bir keratinizasyon mevcuttu. Bu papillaları, papilla filiformis'lerden ayıran papilla yarığı oldukça belirgindi. Bağ dokunun yapmış olduğu mikroskobik papillalar görüldü. Üç bölgede de bu papillaların tepesinde epitel tabakaya gömülü tat tomurcukları tespit edildi (Şekil 7a). Bu tat tomurcukları, tat poruslarıyla ağız boşluğuna açılmaktaydı. Tat tomurcuklarında açık boyalı ve koyu boyalı iki tip tat tomurcuğu hücresi gözlendi (Şekil 7b).

Yuvarlak veya oval şekilli irili ufaklı papilla vallata'lar, dilin torus lingua'sının postero-lateral'inde iki sıra halinde gözlendi. Bu papillaların sayısı toplamda 26-32 arasında değişmekteydi (Şekil 8a).

Taramalı elektron mikroskobik incelemede, papilla vallata'ların en küçüklerinin çapı 487-591 $\mu \mathrm{m}$, en büyüklerinin çapı ise $838 \mu \mathrm{m}-1.47 \mathrm{~mm}$ arasında 
değişmekteydi (Şekil 8b). Papillalar derin bir hendekle çevriliydi. Bu papilla hendeklerinin bir annülar ped ile çevrili oldukları tespit edildi (Şekil 9a). Papilla yüzeylerinden yapılan yüksek büyültmelerde oldukça düzgün bir yüzeye sahip oldukları görüldü. Papilla vallata'ların üst yüzünde tat porusları görülmedi. Yüksek büyütmelerde yüzey epitelinde micropit ve microridge'ler tespit edildi (Şekil 9b).

Işık mikroskobik incelemede papilla vallata'lar, çok katlı yassı bir epitel tabaka ile örtülüydü. Papilla yüzeylerinde zayıf bir keratin tabaka gözlendi. Bağ dokunun papilla yüzey epiteline doğru mikroskobik papillalar yaptığı görüldü. Tükürük bezlerinin akıtıcı kanallarının papilla hendeklerinin kaidesine açıldıkları gözlendi. Tat tomurcukları, papillaların hendeğe bakan medial duvarlarında intraepiteliyal olarak tespit edildi. (Şekil 10a). Papilla valata tat tomurcuklarının tat poruslarıyla papilla hendeklerine açıldıkları görüldü. Tat tomurcuklarında açık ve koyu boyalı tat tomurcuğu hücreleri tespit edildi (Şekil 10b)

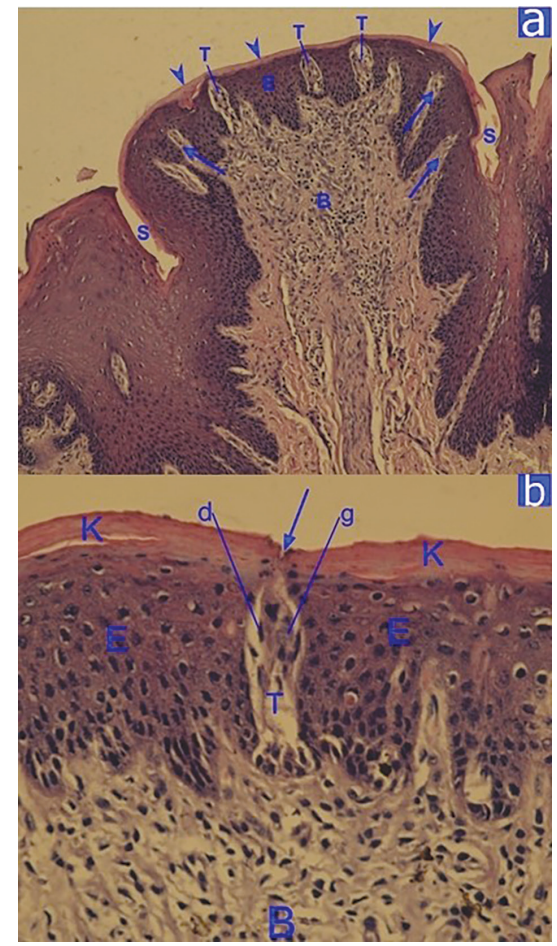

Şekil 7-a) Dil ucundaki papilla fungiformis'lerin ışık mikroskopik görüntüsü (H\&E). E: Çok katlı yassı epitel, B: bağ doku, T: tat tomurcukları, S: papilla yarığı, ok başları: keratinize tabaka, oklar: bağ dokunun epitele doğru yapmış olduğu mikroskobik papillalar. b) Papilla fungiformis'te bir tat tomurcuğunun ışık mikroskobik görünümü (H\&E). E: Epitel tabaka, B: Bağ doku, T: tat tomurcuğu K: Keratinize tabaka, d: koyu boyalı tat tomurcuğu hücresi g: açık boyalı tat tomurcuğu hücresi, Ok: Tat porusu.

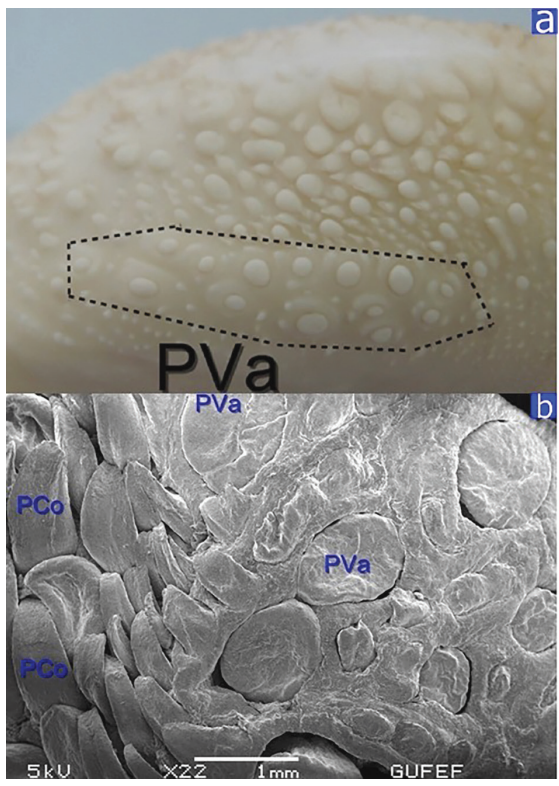

Şekil 8-a) Papilla vallataların makroskobik görünümü. PVa: papilla vallata'lar. b) Papila vallata'ların taramalı elektron mikroskobik görünümü. PVa: Papilla vallata'lar, PCo: Papilla conica'lar.

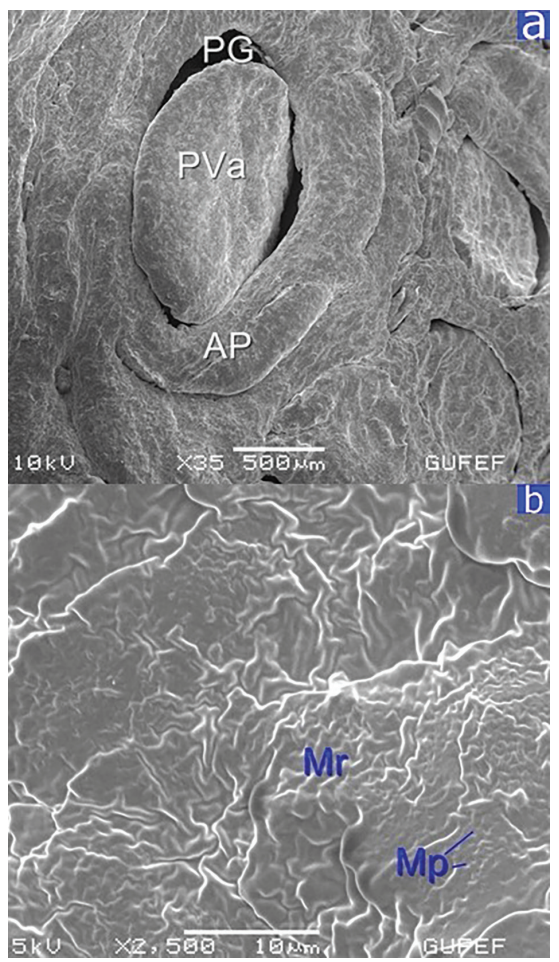

Şekil 9-a) Bir papilla vallata'nın taramalı elektron mikroskobik görünümü. PVa: Papilla vallata, PG: Papilla vallata hendeği, AP: Annuler ped. b) Bir papilla vallata'nın taramalı elektron mikroskopta yüksek büyültmede görünümü. $\mathbf{M p : ~ P a p i l l a ~ y u ̈ z e y ~}$ epitelindeki çukurlar, Mr: Papilla yüzey epitelindeki çıkıntılar. 


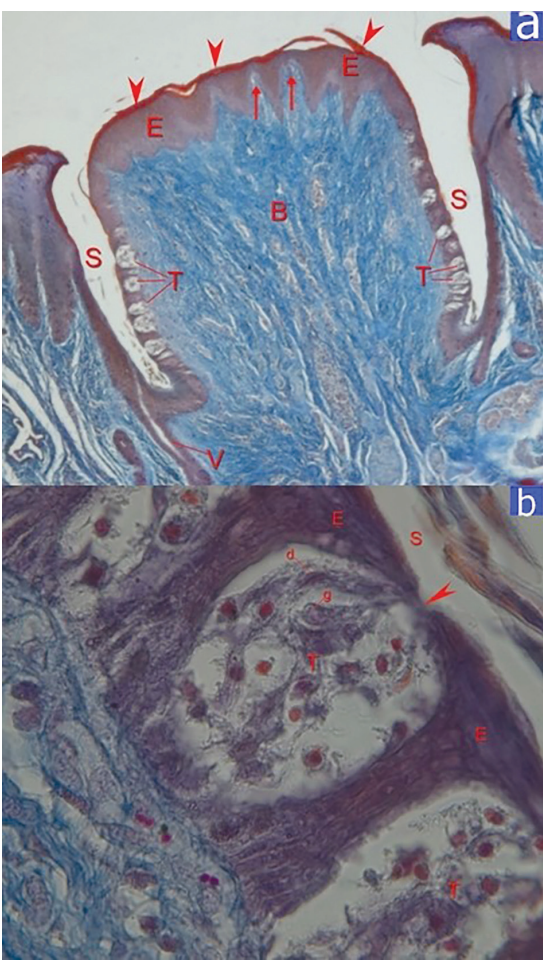

Şekil 10-a) Papilla vallata'nın ışık mikroskobik görünümü: E: Çok katlı yassı epitel, B: Bağ doku, S: Papilla hendeği, T: Tat tomurcukları, V: Von Ebner bezinin akıtıcı kanalı, Ok başları: Keratinize tabaka, Oklar: Mikroskobik papillalar. Mallory'nin Üçlü boyaması. b) Papilla vallata'daki bir tat tomurcuğunun ışık mikroskopik görünümü. E: Çok katlı yassı epitel, T: Tat tomurcukları, S: Papilla hendeği, d: koyu boyalı tat tomurcuğu hücresi, g: açık boyalı tat tomurcuğu hücresi, ok başı: papilla hendeğine açılan tat porusu. Mallory'nin üçlü boyaması.

\section{Tartışma ve Sonuç}

Çift tırnaklılardan (Artiodactyla) inek (Chamorro ve ark. 1986) ve bilinen en küçük çift tırnaklı olan cüce geyikte (Agungpriyono ve ark. 1995) papilla fungiformis, papilla vallata ve papilla foliata olmak üzere 3 tip tat papillası, su aygırında ise (Yoshimura ve ark. 2009) papilla fungiformis ve papilla foliata olmak üzere iki tip tat papillası bulunduğu bildirimlerinin aksine Ankara keçisi dilinde papilla fungiformis ve papilla vallata olmak üzere iki tip tat papillası tespit edilmiştir.

Ankara keçisinde papilla fungiformis'ler, Japon keçi antilobu (Funato ve ark. 1985; Takayuki ve ark. 2002), Çin munçağı (Zheng ve Kobayashi 2006), Akkaraman koyunu (Harem ve ark. 2009), Zavot ineği (Karadag Sarı ve ark. 2010), gazel (Kocak Harem ve ark. 2011) ve alpakaya (Gozdziewska-Harłajczuk ve ark. 2015) benzer şekilde küçük ve büyük olmak üzere iki tipti ve bunlardan dil ucunun üst ve altındaki papilla fungiformis'lerin dil gövdesinin yanları ve torus lingua'da yer alanlardan daha küçük oldukları tespit edildi. Ancak bu bulguların aksine Agungpriyono ve ark. (1995) cüce geyikte papilla fungiformis'lerin dilin ucunda yoğun ve daha büyük olduğunu, Yanping ve ark. (2016) sığır-yakda papilla fungiformis'lerin sayısının dil gövdesinden dil ucuna doğru kademeli olarak azaldıklarını bildirmişlerdir.

Evcil ve yabani bazı ruminantlarda (Atoji ve ark. 1998; Kumar ve ark. 1998; Tadjalli ve Pazhoomand 2004; Zheng ve Kobayashi 2006; Kurtul ve Atalgın 2008; Goodarzi ve Hoseini 2015) ve tek hörgüçlü develerde (Qayyum ve ark. 1988) papilla fungiformis'lerin kendilerini papilla filiformis'lerden ayıran derin bir sulcus'a sahip olduğu bildirimleri bu çalışmada tespit edilmiştir. Ancak gazel (Kocak Harem ve ark. 2011) ve pampa geyiği (Erdoğan ve Perez 2013) papilla fungiformis'lerinde bu sulcus'un bulunmadığı bildirilmiştir.

Ankara keçisine benzer şekilde inek (Chamorro ve ark. 1986), cüce geyik (Agungpriyono ve ark. 1995), pampa geyiği (Erdoğan ve Perez 2013), Markhoz keçisi (Goodarzi ve Hoseini 2015), Anadolu mandası (Can ve Atalgın 2015), alpaka (GozdziewskaHarłajczuk ve ark. 2015) ve Karacabey merinosunda (Can ve ark. 2016) papilla fungiformis'ler yüzeyinde tat poruslarının bulunduğu bildirilmiştir. Bu çalışma bulgularının aksine Jamunapari keçisi (Kumar ve ark. 1998), Saanen keçisi (Kurtul ve Atalgın 2008) ve Akkaraman koyununda (Harem ve ark. 2009) papilla fungiformis'ler yüzeyinde tat porusu bulunmadığı bildirilmiştir.

Jamunapari keçisi (Kumar ve ark. 1998), pampa geyiği (Erdoğan ve Perez 2013), Anadolu mandası (Can ve Atalgın 2015), Markhoz keçisi ( Goodarzi ve Hoseini 2015), alpaka (Gozdziewska-Harłajczuk ve ark. 2015) ve Karacabey merinosunda (Can ve ark. 2016) papilla fungiformis'ler yüzeyinden yapılan yüksek büyültmede görülen yüzey epitel hücreler bu çalışmada da tespit edilmiştir. Cüce geyik (Agungpriyono ve ark. 1995), Jamunapari keçisi (Kumar ve ark. 1998), Anadolu mandası (Can ve Atalgın 2015) ve alpakada (Erdoğan ve ark. 2016) microridge'ler bulunduğu bildirimleri ile Karacabey merinosunda (Can ve ark. 2016) epitel hücre yüzeylerinde micropit'lerin bulunduğu bildirimi bu çalışma sonuçları ile uyumluydu.

Cüce geyik (Agungpriyono ve ark. 1995) ve Zavot ineğinde (Karadag Sarı ve ark. 2010) bildirilenlere benzer şekilde ışık mikroskobik incelemede, 
papilla fungiformis'lerin çok katlı yassı bir epitel tabakaya sahip oldukları tespit edilmiştir. Sunulan çaIışmada papilla fungiformis'lerde görülen zayıf bir keratinizasyon bulgusu, cüce geyik (Agungpriyono ve ark. 1995), Akkaraman koyunu (Harem ve ark. 2009), alpaka (Gozdziewska-Harłajczuk ve ark. 2015) ve sığır-yakda (Yanping ve ark. 2016) bildirilenlere benzer olduğu saptandı.

Gozdziewska-Harłajczuk ve ark. (2015) alpaka dilinde papilla fungiformis'lerin bağ dokusunun papiller yüzeyi sıklıkla penetre etmedikleri bildiriminin aksine mevcut çalışmada bağdokunun yüzeye yapmış oldukları mikroskobik papillalar tespit edilmiştir. Akkaraman koyununda (Harem ve ark. 2009) papilla fungiformis'lerde tat tomurcuklarının bulunmadığı bildirilmiştir. Gazel (Kocak Harem ve ark. 2011) ve koyunda (Erdoğan ve Sağsöz 2018) dilin gövdesi ve üst yüzünde bulunan birinci tip ve küçük papilla fungiformis'lerde tat tomurcuklarının bulunduğunu ancak ikinci tip ve daha büyük olan torus lingua'da yer alan papillalarda tat tomurcuklarının yer almadığını bildirmişlerdir. Çalışmada üç bölgede de bu papillaların tepesinde epitel tabakaya gömülü tat tomurcukları tespit edildi ve bu tat tomurcukları, tat poruslarıyla ağız boşluğuna açılmaktaydı. Tabata ve ark. (2006) sığır papilla fungiformis tat tomurcuklarında tip 1 ve tip 2 tat hücreleri bulunduğu bildirimine benzer şekilde tat tomurcuklarında açık boyalı ve koyu boyalı iki tip tat tomurcuğu hücresi de gözlendi.

Bu çalışmada yuvarlak veya oval şekilli irili ufaklı papilla vallata'lar, dilin torus lingua'sının postero-lateral'inde iki sıra halinde gözlendi. Papilla valata'ların sayısı toplamda 26-32 arasında değişmekteydi. Alpakada 6-8 adet (Gozdziewska-Harłajczuk ve ark. 2015), alpakada 2-3 adet sol, 3-4 adet sağda, lamada 4 adet sağ, 3-4 adet solda (Erdoğan ve ark. 2016), pampa geyiğinde 10-18 adet (Erdoğan ve Perez 2013), Anadolu mandasında 23 adet (Can ve Atalgın 2015), gazel (Kocak Harem ve ark. 2011), Zavot ineği (Karadag Sarı ve ark. 2010) ve Saanen keçisinde (Kurtul ve Atalgın 2008) 26 adet, sığır-yakda 28 adet (Yanping ve ark. 2016), antilopta (Emura ve ark. 1999) ve berberi koyununda 30 adet (Emura ve ark. 2000), Akkaraman koyununda 36 adet (Harem ve ark. 2009) ve Karacabey merinosunda 3852 adet (Can ve ark. 2016) papilla vallata bulunduğu bildirilmiştir. Ankara keçisindeki papilla vallata'ların sayısı gazel (Kocak Harem ve ark. 2011), Zavot ineği (Karadag Sarı ve ark. 2010) ve Saanen keçisi (Kurtul ve Atalgın 2008) papilla vallata sayıları ile benzerdi.

Cüce geyik (Agungpriyono ve ark. 1995), Jamunapari keçisi (Kumar ve ark. 1998), Saanen ke- çisi (Kurtul ve Atalgın 2008), Zavot ineği (Karadag Sarı ve ark. 2010), gazel (Kocak Harem ve ark. 2011), Markhoz keçisi (Goodarzi ve Hoseini 2015), alpaka (Erdoğan ve ark. 2016; Gozdziewska-Harłajczuk ve ark. 2015) ve Karacabey merinosunda (Can ve ark. 2016) bildirilenlere benzer şekilde Ankara keçisi papilla vallata'ları derin bir hendekle çevriliydi ve bu papilla hendekleri bir annular pedlere sahipti. Akkaraman koyununda (Harem ve ark. 2009) papilla vallata'ların tek tek veya bazen 2-3'lü gruplar halinde bir hendekle çevrili ve belirgin bir annular pede sahip olmadıkları, koyunlarda (Erdoğan ve Sağsöz 2018) bazı papilla vallata'larda annular ped bulunmadığı bildirimleri çalışmamızda görülmemiştir.

Pampa geyiği (Erdoğan ve Perez 2013) ve guanakoda (Erdoğan ve ark. 2016) papilla vallata'ların düzgün bir yüzeye sahip olduğu bildirimleri sunulan çalışmada da tespit edilmiştir. Çalışma bulgularının aksine Kocak Harem ve ark. (2011) gazelde papilla valata'ların düzensiz bir yüzeye sahip olduklarını, El Sharaby ve ark. (2012) tek hörgüçlü devede papilla vallata'ların çevresinin düz, merkezinde ise dar hendekler olduğunu ve mikroplikasyonun bulunduğunu bildirmişlerdir.

Chamorro ve ark. (1986) inekte papilla vallata hendeği ve papilla yüzeyine açılan tat porusları bulunduğunu, Goodarzi ve Hoseini (2015) Markhoz keçisinde, Yanping ve ark. (2016) sığır-yakda ve Erdoğan ve Sağsöz (2018) koyunda papilla vallata yüzeyine açılan tat poruslarının bulunduğunu bildirmişlerdir. Gozdziewska-Harłajczuk ve ark. (2015), alpakada papilla vallata'da bulunan psüdo papillalar yüzeyinde tat poruslarının bulunduğunu, El Sharaby ve ark. (2014) buffaloda papilla hendeklerine bitişik tat poruslarının yer aldığını, El Sharaby ve ark. (2012) tek hörgüçlü develerde genç ve yaşlılarda primer ve sekonder hendekler yakınında tat poruslarının yerleştiğini bildirmişlerdir. Bu çalışmada papilla vallata yüzeylerinde tat porusu görülmemiştir.

Agungpriyono ve ark. (1995) cüce geyikte papilla vallata yüzey epitelinde mikroridge'ler bulunduğu bildirimine benzer şekilde yüksek büyütmelerde papilla vallata yüzey epitelinde micropit ve microridge'ler tespit edildi.

Cüce geyik (Agungpriyono ve ark. 1995), Zavot ineği (Karadag Sarı ve ark. 2010), tek hörgüçlü deve (El Sharaby ve ark. 2012), buffalo (El Sharaby ve ark. 2014) ve koyunda (Erdoğan ve Sağsöz 2018) ışık mikroskobik incelemede papilla vallata'ların çok katlı yassı bir epitel tabakaya sahip olduğu bildirimleri çalışmamızda da gözlendi. Cüce geyik (Agungpriyono ve ark. 1995), Akkaraman koyunu (Harem ve ark. 
2009), alpaka (Gozdziewska-Harłajczuk ve ark. 2015) ve koyunda (Erdoğan ve Sağsöz 2018) papilla vallata yüzeylerinde zayıf bir keratinizasyon olduğu bildirilmiştir. Kocak Harem ve ark. (2011), gazelde orta kalınlıkta bir keratin tabaka bulunduğunu bildirmiştir. Bu çalışmada cüce geyik (Agungpriyono ve ark. 1995), Akkaraman koyunu (Harem ve ark. 2009), alpaka (Gozdziewska-Harłajczuk ve ark. 2015) ve koyunda (Erdoğan ve Sağsöz 2018) bildirilenlere benzer şekilde zayıf bir keratin tabaka gözlendi. Cüce geyik (Agungpriyono ve ark. 1995), sığır (Tabata ve ark. 2003), Akkaraman koyunu (Harem ve ark. 2009), Zavot ineği (Karadag Sarı ve ark. 2010), gazel (Kocak Harem ve ark. 2011), tek hörgüçlü deve (El Sharaby ve ark. 2012), buffalo (El Sharaby ve ark. 2014), alpaka (Gozdziewska-Harłajczuk ve ark. 2015) ve koyunda (Erdoğan ve Sağsöz 2018) bildirilenlere benzer şekilde papilla vallata'daki tat tomurcukları, papillaların hendeğe bakan medial duvarlarında intraepiteliyal olarak tespit edildi ve bu tat tomurcukları tat poruslarıyla papilla hendeklerine açılmaktaydı. Tabata ve ark. (2003) sığırda tip 1 ve tip 2 olmak üzere papilla vallata tat tomurcuklarında iki tip tat tomurcuğu hücresi bulunduğunu bildirmiştir. Bu çalışmada tat tomurcuklarında açık ve koyu boyalı olmak üzere iki tip tat tomurcuğu hücreleri tespit edilmiştir. Cüce geyik (Agungpriyono ve ark. 1995), Zavot ineği (Karadag Sarı ve ark. 2010), tek hörgüçlü deve (El Sharaby ve ark. 2012), alpaka (Gozdziewska-Harłajczuk ve ark. 2015) ve koyunda (Erdoğan ve Sağsöz 2018) tükürük bezlerinin akıtıcı kanallarının papilla vallata hendeklerinin kaidesine açıldıkları bildirimi çalışmamızda da tespit edilmiştir.

Sonuç olarak; Ankara keçisi dilindeki tat papillalarının ışık ve taramalı elektron mikroskobik bulguları, diğer evcil ve yabani ruminant dilindeki tat papillalarından elde edilen bulgular ile karşılaştırılmıştır. Bunun sonucunda benzerlikler ve farklılıklar olduğu görülmüştür. Görülen bu farklııkların Ankara keçisinin besin türü ve beslenme şekillerinden kaynaklanabileceği düşünülmektedir. Bu çalışmadan elde edilen verilerin alanındaki bilgi birikimine katkı sağlayacağı öngörülmektedir.

\section{Deney Hayvanları Kullanımı Etik Kurulu ve diğer etik kurul kararları ve izinler: "Hayvan Deneyleri Etik Kurullarının Çalışma Usul ve Esaslarına Dair Yönetmelik" Madde $8(k)$ bendi 2. maddesi gereği izin alınmamıştır.}

Maddi Destek ve Çıkar iliş̧kisi: Çalışmayı maddi olarak destekleyen kişi/kuruluş yoktur ve yazarların herhangi bir çıkara dayalı ilişkisi yoktur.
Yazarların Katkı Oranı: BT çalışmanın planlanma$\mathrm{SI}$, materyal temini ve örneklerin hazırlanması, SC taramalı elektron mikroskop incelemesi, NÖK ışık mikroskop incelemesi, BT SEM ve ışık mikroskobik görüntülerin değerlendirilmesi ve makalenin yazımı.

\section{Kaynaklar}

Agungpriyono S, Yamada J, Kitamura N, Nisa C, Sigit K, Yamamoto Y. (1995). Morphology of the dorsal lingual papillae in the lesser Mouse deer, Tragulus javanicus. J Anat. 187, 635-640.

Atoji Y, Yamamoto Y, Suzuki Y. (1998). Morphology of the tongue of a male formosan serow (Capricornis crispus swinhoei). Anat Histol Embryol. 27, 17-19.

Can M, Atalgın SH. (2015). Scanning electron microscopic study of the lingual papillae in the Anatolian water buffalo. Int $J$ Morphol. 33, 855-859.

Can M, Atalgın ŞH, Ateş S, Takçı L. (2016). Scanning electron microscopic study on the structure of the lingual papillae of the Karacabey Merino sheep. Eurasian J Vet Sci. 32, 130-135.

Chamorro CA, de Paz P, Sandoval J, Fernandez JG. (1986). Comparative scanning electron microscopic study of the lingual papillae in two species of domestic mammals (Equus caballus and Bos taurus). I. Gustatory papillae. Acta Anat. 125, 83-87.

El Sharaby AA, Alsafy MA, El-Gendy SA, Wakisaka S. (2012). Morphological characteristics of the vallate papillae of the one-humped camel (Camelus dromedarius). Anat Histol Embryol. 41, 402-409.

El Sharaby AA, El-Gendy SA, Alsafy MA, Nomir AG, Wakisaka S. (2014). Morphological variations of the vallate papillae in some mammalian species. Anat Sci Int. 89, 161-170, DOI 10.1007/s12565-013-0215-9.

Emura S, Tamada A, Hayakawa D, Chen H, Yano R, Shoumura S. (1999). Morphology of the dorsal lingual papillae in the blackbuck, (Antilope Cervicapra). Okajimas Folia Anat Jpn. 76, 247-254.

Emura S, Tamada A, Hayakawa D, Chen H, Shoumura S. (2000) Morphology of the dorsal lingual papillae in the Barbary sheep. Ammotragus lervia. Okajimas Folia Anat Jpn. 77, 39-46.

Erdoğan S, Perez W. (2013). Anatomical and scanning electron microscopic studies of the tongue in the pampas deer (Cervidae: Ozotoceros bezoarticus, Linnaeus 1758). Micro Res Tech. 76, 1025-1034.

Erdoğan S, Villar Arias S, Pérez W. (2016). Morphofunctional structure of the lingual papillae in three species of south american camelids: Alpaca, Guanaco, and Llama. Microsc Res Tech. $79,61-71$

Erdoğan S, Sağsöz H. (2018). Papillary architecture and functional characterization of mucosubstances in the sheep tongue. Anat Rec. 301, 1320-1335.

Fonseca ET, Oliveira CM, Franciolli ALR, Miglino MA. (2011). Characteristics of dorsal lingual papillae of the goat (Capra hircus): Light and scanning electron microscopy study. Pesq Vet Bras. 31, 67-73.

Funato H, Atoji Y, Suzuki Y, Sugimura M. (1985) Morphological studies on the tongue of wild Japanese serows, Capricornis crispus. Res Bull Fac Agr Gifu Univ. 50, 205-219.

Goodarzi N, Hoseini TS. (2015). Fine structure of lingual papillae in the Markhoz goat (Iranian Angora): A scanning electron microscopic study. Int J Zool Res. 11, 160-168. 
Gozdziewska-Harłajczuk K, Kleckowska-Nawrot J, Janeczek M, Zawadzki M. (2015). Morphology of the lingual and buccal papillae in alpaca (Vicugna pacos) - Light and scanning electron microscopy. Anat Histol Embryol. 44, 345-360.

Harem iş, Karadağ Sarı E, Koçak Harem M. (2009). Akkaraman koyununda dorsal dil papillalarının ışık ve taramalı elektron mikroskopik yapısı. Kocatepe Vet J. 2, 8-14.

Iwasaki S. (2002). Evolution of the structure and function of the vertebrate tongue. J Anat. 201, 1-13.

Karadag Sarı E, Kocak Harem M, Harem IS. (2010). Characteristics of dorsal lingual papillae of Zavot cattle. J Anim Vet Adv. 9, 123-130.

Kocak Harem M, Harem IS, Karadag Sari E, Aydin MF. (2011). Light and scanning electron microscopic study of the dorsal lingual papillae of the Goitered Gazelle (Gazelle subgutturosa). J Anim Vet Adv. 10, 1906-1913.

Kumar P, Kumar S, Singh Y. (1998). Tongue papillae in goat: a scanning electron-microscopic study. Anat Histol Embryol. 27, 355-357.

Kurtul I, Atalgın SH. (2008). Scanning electron microscopic study on the structure of the lingual papillae of the Saanen goat. Small Rumin Res. 80, 52-56.

Qayyum MA, Fatani JA, Mohajir AM. (1988). Scanning electron microscopic study of the lingual papillae of the one humped camel, Camelus dromedarius. J Anat. 160, 21-26.
Tabata S, Wada A, Kobayashi T, Nishimura S, Muguruma M, Iwamoto H. (2003). Bovine circumvallate taste buds: taste cell structure and Immunoreactivity to $\alpha$-Gustducin. Anat Rec. 271A, 217- 224.

Tabata S, Kudo KI, Wada-Takemura A, Nishimura S, Iwamoto H. (2006). Structure of bovine fungiform taste buds and their immunoreactivity gustducin. J Vet Med Sci. 68, 953-957.

Tadjalli M, Pazhoomand R. (2004). Tongue papillae in lambs: a scanning electron microscopic study. Small Rumin Res. 54, 157-164.

Takayuki Y, Tomoichiro A, Kobayashi K. (2002). Comparative anatomical studies on the stereo structure of the lingual papillae and their connective tissue cores in the Japanese serow and Bighorn sheep. Jap J Oral Biol. 44, 127-141.

Yanping D, Shiyuan Y, Baoping S. (2016). Anatomical and histological characteristic of the tongue and tongue mucosa linguae in the cattle-yak ( $\times$ ). Front Biol. 11, 141-148.

Yoshimura K, Hama N, Shindo J, Kobayaski K, Kageyama I. (2009). Light and scanning electron microscopic study on the tongue and lingual papillae of the hippopotamus, Hippopotamus amphibious. Anat Rec. 292, 921-934.

Zheng JH, Kobayashi K. (2006). Comparative mophological study on the lingual papillae and their connective tissue cores (CTC) in revees Muntjac deer (Muntiacus reeesi). Ann Anat. 188, 555-564. 